propriate. It is often the case that these follow-up patients are not seen by the consultant for a number of visits and when he does see the patient it is quite obvious that there has been no need at all for continued hospital attendance. This therefore is another very important function of the consultant in the medical clinic.

With the large number of new patients that are continually referred to the medical clinics and the large number of follow-up patients, it is necessary to share the work load with the junior staff, but unfortunately this may mean some duplication of effort. I did try in my paper to indicate that the experienced consultant will need only to supplement the information provided by the registrar or SHO as on many occasions a lot of the basic information has already been obtained. Another important point justifying the presence of junior staff in the outpatient department is for training purposes, which I am sure you will agree is an important aspect of their education.

I should like to make one other comment, in relation to the letter from Dr D A Haslam (21 July, p 207). He has suggested that it is a widespread practice for general practitioners to carry out routine screening tests before referring the patient to the hospital clinic. I have not, in fact, found this to be the usual procedure in this area, and in the light of my findings it is perhaps a practice not to be encouraged.

\section{Department of Medicine,} Barnsley, S Yorks

Gerald SANDLER

\section{Not an ethical dilemma}

SIR,-Dr John W Todd's letter (11 August, p 391) regarding doctors' pronouncing unfitness for work based on the pre-employment medical examination show how little is understood about the purpose of these assessments.

Occupational health physicians seldom give unqualified "fit/unfit" reports, as they consider that their duty is to assist management both in placing people at work and in keeping them in employment. Rejection from work on medical grounds plays little part and usually shows failure by the doctor in presenting an appropriate assessment to management.

Medical examination is the basis from which the report to management should indicate any work restrictions that may be required to keep an applicant in employment as long as possible, and to allow management to adapt conditions of work so that the employee is not at risk. Of course, occasionally the restrictions are such that management cannot place the person in employment, but it is a decision of management to reject, not of the doctor, who should be persuading management to do its best to accommodate the employee. Doctors do not "hire or fire" people and it is only bad managements that pass the responsibility on to their medical advisers. Management quite rightly has to consider both statutory responsibilities and the investment in the individual over a long period, and the medical assessment remains an essential part of this decision making. The problem is often that doctors do not know how to present the essential data required by management from their clinical findings.
SIR,-I should like to point out a serious anomaly in Dr J W Todd's letter (11 August, p 391). Doctors working in occupational health do not work just on behalf of their employer, and do not need to have the Hippocratic Oath adjusted for themselves in any way whatsoever.

One of the reasons for medically examining people before they are employed in a certain industry is to make sure that they are fit for that particular job, without in any way being a liability either to themselves or to other people. No one would really think it correct to employ as a hospital doctor or as a general practitioner a man who was an alcoholic and a threat to his patients. No more is it correct to let someone with chronic septic conditions work in a kitchen; or a man with chronic backache take a job as a pumper-dipper, where the work involves much bending, climbing, lifting, etc; or allow a man with uncontrolled syncopal attacks to drive a tanker laden with inflammable fuel around our countryside and through our towns. The main purpose of these pre-employment medical examinations is to ascertain whether a person is fit for a particular job (and different jobs obviously have different criteria), with the best intentions for the applicant and his fellow men borne in mind. It is never done as part of working for the employer.

In fact, we go to great lengths to preserve the patient's full confidentiality, and to liaise as much as possible with the patient's general practitioner in the event of finding a significant abnormal sign. In this and other ways we hope to help a person, not hinder him.

Coryton Refinery,

Mobil Oil Company Limited Stanford-le-Hope, Essex SS17 9LL

J R B COOPER

\section{Anatomists' and physiologists' pay}

SIR,-Dr J H Jessop's Personal View (18 August, p 439) of being a demonstrator reminds us, in its very first section, that anatomy is a specifically medical subject, with all that is implied for teachers thereof. I wonder how many practising doctors, grateful even for the eccentricities of their old teachers in basic medical sciences, realise how appallingly they are paid in comparison with almost all other registered medical practitioners?

At the last count (1977), there were only 164 (aging) medically qualified career anatomists and 142 physiologists in the UK. Their top salary prospects at senior lecturer/reader grade are $£ 10775 \mathrm{pa}$, with no eligibility for distinction awards or other pensionable extras. This means that they can at best earn $£ 3484$ a year less than a full-time consultant without a distinction award till the end of his days, or $£ 4495$ less than the lowest grade (Band E) of area medical officers. So apart from bad career prospects and losses in the earlier, nonsenior, part of his service the medically qualified preclinical teacher will, in the last 20 years of service at senior grade, earn nearly $£ 100000$ less than his lowest-paid consultant or community colleagues, to be followed by a much lower rate of pension ( $£ 5387$ a year).

To bring the salaries of the 233 medically qualified senior anatomists and physiologists ( 85 of whom are professors) up to the level of full-time consultants and those of the 73 lecturers to the level of registrars or senior registrars would cost considerably less than
$£ 1 \mathrm{~m}$ a year, which is almost nothing in terms of total NHS or university wage bills. Unless something is done, your sons and daughters and all other future medical students will not be taught by people with experience of and education in medicine. Yet 302 of us, alone, cannot do much about it. What will our tens of thousands of hospital and GP colleagues do ?

\section{DAVID BOWSHER}

University Department of Anatomy, Liverpool L69 3BX

\section{Vocational training}

SIR,-Dr R D France (18 August, p 446) has some very strange ideas about vocational training schemes, entry into which does not lie in the gift of appointed representatives of the Royal College of General Practitioners. Having recently completed such a scheme I can assure Dr France that I consider myself neither an automated Balint model nor an amateur psychosexologist.

I have found the knowledge and skill I acquired during my training for the most part highly relevant and useful. I was not taught by a "small clique of zealots," but by many "competent and kindly" general practitioners, who I am sure would not wish to be the "irascible and eccentric" doctors that the public of Dr France's acquaintance expect to see. It is ludicrous to suggest that patients might expect to "apply for the services of the primary health care team"; however, many of my patients value the attention given to them by the practice or district nurse, or the health visitor.

No empire has been built by any fringe pressure group; the foundation built for the continuance and furtherance of the highest standards of care in general practice are firm, and will I believe not fall.

C A Stubbings

Exmouth, Devon

\section{Hospital practitioner and clinical} assistant grades

SIR,-I am stimulated by the letter from Dr E B Allen (11 August, p 393) to write on this subject. I am quite sure his local consultants are not at all jealous of general practitioners' pay. They may feel, as I do, that there is considerable injustice in making the hospital practitioner grade with its six annual increments available to GPs only, leaving others as clinical assistants. I am very conscious of the value of GPs and other part-time doctors to the hospital service. In 25 years I have masterminded the appointment of three GPs and two married women doctors as clinical assistants to my department. Each one provides an equally valuable service and it would be wrong if the married women were paid less because they are not GPs.

It is high time married women doctors working parttime in hospital were appreciated for the valuable work they do-often in the less popular specialties. Most of them do four or more weekly sessions and acquire considerable expertise as this is their total professional interest and commitment. They are an undemanding group - a boon to hospital 